\title{
Newborn Screening for Lysosomal Storage Disorders
}

\author{
Roy W. A. Peake ${ }^{1}$ Olaf A. Bodamer ${ }^{2,3}$ \\ 1 Department of Laboratory Medicine, Boston Children's Hospital, \\ Boston, Massachusetts, United States \\ 2 Division of Genetics and Genomics, Department of Medicine, Boston \\ Children's Hospital, Boston, Massachusetts, United States \\ ${ }^{3}$ Harvard Medical School, Boston, Massachusetts, United States
}

\begin{abstract}
Address for correspondence Olaf A. Bodamer, MD, PhD, FACMG, FAAP, Boston Children's Hospital, 300 Longwood Avenue, Boston, MA 02115, United States (e-mail: olaf.bodamer@childrens.harvard.edu).
\end{abstract}

J Pediatr Genet 2017;6:51-60.

\begin{abstract}
Keywords

- dried blood spot

- filter card

- mass spectrometry

Newborn screening is one of the most important public health initiatives to date, focusing on the identification of presymptomatic newborn infants with treatable conditions to reduce morbidity and mortality. The number of screening conditions continues to expand due to advances in screening technologies and the development of novel therapies. Consequently, some of the lysosomal storage disorders are now considered as candidates for newborn screening, although many challenges including identification of late-onset phenotypes remain. This review provides a critical appraisal of the current state of newborn screening for lysosomal storage disorders.
\end{abstract}

\section{Introduction}

Newborn screening (NBS) is a public health program with the purpose of identifying presymptomatic newborn infants with treatable conditions associated with significant morbidity and mortality. Since its implementation for the detection of phenylketonuria (PKU) over 50 years ago, NBS has evolved to one of the most effective public health initiatives worldwide. Approximately 4 million newborn infants in the United States are screened annually for a minimum of 29 core conditions, resulting in approximately 12,000 diagnoses every year. ${ }^{1}$

The concept of NBS was coined by Robert Guthrie for PKU in the early 1960s, when he developed a bacterial inhibition assay for mass screening through detection of abnormal blood phenylalanine levels. ${ }^{2}$ Dried blood spots (DBS) were punched from a filter card ("Guthrie card") and transferred to an agar plate containing a bacterial species that only grew in the presence of phenylalanine. ${ }^{2}$ Guthrie proceeded to develop similar assays for the detection of maple syrup urine disease (MSUD), homocystinuria, and galactosemia. ${ }^{3}$ However, it was not until the late 1960s when an attempt was made to define criteria ("Wilson-Jungner" criteria) applicable to conditions

received

June 9, 2015

accepted after revision

August 28, 2015

published online

December 2, 2016 in NBS programs. ${ }^{4}$ Although these criteria laid the foundation for future expansion of NBS programs, the addition of conditions such as congenital hypothyroidism, sickle cell anemia, congenital adrenal hyperplasia (CAH), and biotinidase deficiency was largely driven through the development of novel screening assays. ${ }^{5-8}$

A major milestone in NBS was achieved in the mid-1980s with the development of the electrospray ionization interface for mass spectrometry. ${ }^{9}$ The potential of this device for the screening for inborn errors of metabolism (IEM) was first realized by Millington in 1990, when he reported the application of electrospray ionization tandem mass spectrometry (ESI-MS/MS) to acylcarnitine profiling using DBS. ${ }^{10}$ This analytical approach offered multiplex high-throughput capabilities to NBS laboratories, allowing accurate and efficient detection of multiple disorders with excellent performance characteristics at a relatively low cost. ${ }^{11}$ The introduction of tandem mass spectrometry (MS/MS)-based methods allowed both the expansion of NBS programs, and replacement of the existing traditional screening assays for PKU, MSUD, and homocystinuria. ${ }^{12-15}$

The early population-wide detection of many IEM has led to a reduction in morbidity and mortality, an overall

Copyright $\odot 2017$ by Georg Thieme Verlag KG, Stuttgart · New York
DOI http://dx.doi.org/ 10.1055/s-0036-1593843. ISSN 2146-4596.
Issue Theme Advances in Pediatric
Genetic Tests; Guest Editor: Elizabeth

McCready, PhD, FCCMG 
improvement of clinical outcomes and increased detection rates through the identification of milder phenotypes. ${ }^{16-18}$ The relatively rapid expansion of NBS programs warranted a more standardized approach for inclusion of conditions across the United States, which led the American College of Medical Genetics (ACMG) to convene an expert panel that recommended universal screening of 29 core disorders. ${ }^{19}$ The core panel includes disorders of fatty acid oxidation, disorders of amino acid metabolism (including PKU), disorders of intermediary metabolism (organic acidopathies), hemoglobinopathies, cystic fibrosis, hypothyroidism, CAH, biotinidase deficiency and galactosemia. ${ }^{19}$ Recent additions include severe combined immune deficiency (SCID) and cyanotic heart disease. ${ }^{20}$ It is well recognized that MS/MS will also detect conditions that are not included in the core panel, designated "secondary targets." 19

The nomination of new disorders for NBS in the United States is under the auspices of the Advisory Committee on Heritable Disorders in Newborns and Children. Established under the Public Health Service Act, the committee advises the Secretary of the U.S. Department of Health and Human Services on the application of new technologies, policies, guidelines, and standards to universal NBS testing. ${ }^{20}$ Disorders to be considered for inclusion are nominated through the Nomination and Prioritization Workgroup of the Discretionary Committee on Heritable Disorders in Newborns and Children (DACHDNC). The workgroup will convene additional external review groups including experts for the respective conditions to provide an evidence-based review and recommendation. Pompe disease and mucopolysaccharidosis type I (MPS I) have been recently reviewed and recommended for inclusion into NBS, whereas Fabry disease has been reviewed but not recommended. ${ }^{20}$ Interestingly Krabbe, Niemann Pick, and Gaucher diseases have not been reviewed at all, despite their inclusion in NBS in several states. Most notably, Krabbe disease screening has been performed in New York State since 2006. ${ }^{21}$

\section{Lysosomal Storage Disorders}

Lysosomal storage disorders (LSDs) comprise a heterogeneous group of approximately 50 IEM due to defects in either a lysosomal enzyme, transport, or membrane protein. ${ }^{22}$ The resulting accumulation of intermediate metabolites leads to a variable clinical phenotype, depending on the nature and severity of the defect and organ systems involved. Almost any organ, including the central nervous system, can be affected. ${ }^{23}$ The clinical phenotype represents a continuous spectrum; more severe cases typically present during the neonatal period and infancy, with milder cases presenting during adulthood or not all. Most LSDs are inherited as autosomal recessive traits, whereas few are inherited as X-linked recessive traits. Although individually rare, the cumulative incidence of LSDs may be as high as 1:2,000 live births or higher in certain ethnic groups. ${ }^{24}$ Different modalities of treatment, including enzyme replacement therapy, stem cell transplantation, substrate reduction therapy, and others are available for several LSDs and have been shown to improve outcome. ${ }^{25}$

\section{LSD Assays for Newborn Screening}

Different assays using either fluorometry, MS/MS, or immunoquantification have been used for high-throughput analysis of lysosomal enzymes in DBS (-Table 1).

\section{Enzyme Activity Measurement using Fluorescence}

The pioneering work of Chamoles and coworkers was the first demonstration of using hydrated DBS specimens with standard fluorometric assays. ${ }^{26-31}$ Conventional fluorometric methods have subsequently been developed for at least 14 lysosomal enzymes. ${ }^{32}$ This approach entails assaying the enzyme of interest using an artificial substrate derivatized with a fluorescent tag, such as 4-methylumbelliferone (4-MU). These assays have been successfully adopted for high-throughput analysis, as demonstrated in an NBS pilot study for Pompe disease in Taiwan using a modified 96-well plate version of the conventional 4-MU assay for GLA activity. ${ }^{33}$ However, these methods have restricted capacity for multiplexing, where only one or two enzymes can be assayed reliably using conventional 96-well microplate technology. This has proven to be a major limitation of the method when considering its potential use in NBS programs for LSDs, where economic viability is dependent on analyzing multiple enzymes simultaneously. Multiplexing also provides the flexibility to include additional LSDs in testing profiles. The subsequent development of digital microfluidic chip technology was intended to convert existing conventional fluorometric enzyme assays into high-throughput methods capable of measuring multiple enzymes simultaneously. ${ }^{34-36}$

Digital microfluidics involves the transport of sub-microliter volumes of both sample and enzyme assay components over an array of electrodes under the influence of an electric field. All assay steps including sampling, addition of substrate and reaction buffer, mixing, incubation, quenching, and product detection are performed within a chip on a disposable cartridge. The entire process is fully automated and performed on a small bench-top analyzer. Sista et al described the performance of a 5-plex assay for Pompe, Fabry, Gaucher diseases, MPS I, and MPS II in a small screening pilot study. ${ }^{36} \mathrm{~A}$ digital microfluidics prototype cartridge (Advanced Liquid Logic, Inc., Morrisville, North Carolina, United States) was also used in a screening pilot study for Pompe, Fabry, and Gaucher diseases at the Illinois Department of Public Health laboratories. From a total of 8,012 newborns screened, 7 cases of Fabry disease and 2 of Gaucher disease were detected. Despite improvements in sample throughput, the digital microfluidic plate assays are not able to match the throughput of contemporary MS/MS assays. A single MS/MS instrument has the throughput equal to around 7.8 digital microfluidics plate readers. ${ }^{37}$ There may also be evidence to suggest that MS/MS methods have potentially lower screen false-positive rates than equivalent digital microfluidic methods. As more data becomes available from NBS programs using either technique, more effective comparisons will be feasible.

Fluorometric assays have also been limited by the availability of suitable enzyme substrates and reagents. The production of fluorometric substrates of adequate purity is 
Table 1 Summary of methods used for LSD screening assays

\begin{tabular}{|c|c|c|c|c|c|c|}
\hline \multirow{2}{*}{$\begin{array}{l}\text { Performance } \\
\text { characteristics }\end{array}$} & \multicolumn{6}{|c|}{ Screening method } \\
\hline & $\begin{array}{l}\text { MS/MS } \\
(2014)^{a}\end{array}$ & $\begin{array}{l}\text { MS/MS } \\
(2008)^{b}\end{array}$ & LC-MS/MS & $\begin{array}{l}\text { Standard } \\
\text { fluorometry }\end{array}$ & $\begin{array}{l}\text { Digital } \\
\text { microfluidics }\end{array}$ & Immunoquantification \\
\hline $\begin{array}{l}\text { Low false-positive } \\
\text { rate }\end{array}$ & ++++ & +++ & ++++ & + & +++ & ++ \\
\hline $\begin{array}{l}\text { High sample } \\
\text { throughput }\end{array}$ & ++++ & ++++ & ++++ & + & +++ & ++ \\
\hline $\begin{array}{l}\text { Multiplexing } \\
\text { capability }\end{array}$ & ++++ & ++++ & ++++ & + & ++++ & ++++ \\
\hline Low cost per sample & +++ & +++ & +++ & ++ & +++ & ++ \\
\hline $\begin{array}{l}\text { Reliable supply } \\
\text { of reagents }\end{array}$ & ++++ & ++++ & ++++ & +++ & +++ & + \\
\hline $\begin{array}{l}\text { Complexity of } \\
\text { sample preparation }\end{array}$ & + & ++ & + & +++ & ++ & ++ \\
\hline Dynamic range & +++++ & +++ & +++ & ++ & +++ & +++ \\
\hline $\begin{array}{l}\text { Newborn screening } \\
\text { program(s) } \\
\text { using method(s) }\end{array}$ & $\begin{array}{l}\text { - University of } \\
\text { Washington }\end{array}$ & $\begin{array}{l}\text { - New York } \\
\text { State }\end{array}$ & $\begin{array}{l}\text { - Illinois } \\
\text { - Austria } \\
\text { (Pilot) }\end{array}$ & - Taiwan & - Missouri & - N/A \\
\hline
\end{tabular}

Abbreviations: LSD, lysosomal storage disorder; LS-MS/MS, liquid chromatography mass spectrometry; MS/MS, tandem mass spectrometry; N/A, (data) not available.

${ }^{\text {a}}$ Flow-injection MS/MS assay developed in 2014 using Perkin Elmer reagents.

${ }^{\mathrm{b}}$ Flow-injection MS/MS assay developed in 2008 using Genzyme-CDC reagents.

Table 2 Summary of NBS pilot study data

\begin{tabular}{|c|c|c|c|c|c|}
\hline Program & Started & Method & Number & Observed incidence & False-positive rate \\
\hline Missouri ${ }^{69}$ & 2013 & $\begin{array}{l}\text { Digital microfluidic } \\
\text { enzyme assay }\end{array}$ & 43,701 & $\begin{array}{l}\text { Fabry }(1: 2,913) \\
\text { Gaucher }(1: 43,701) \\
\text { Pompe }(1: 5,463) \\
\text { MPS } 1(1: 14,567)\end{array}$ & $\begin{array}{l}\text { Fabry }(0.025 \%) \\
\text { Gaucher }(0.020 \%) \\
\text { Pompe }(0.009 \%) \\
\text { MPS } 1(0.037 \%)\end{array}$ \\
\hline Washington $^{70}$ & 2012 & MS/MS & 111,544 & $\begin{array}{l}\text { Fabry }(1: 16,667) \\
\text { Pompe }(1: 30,000) \\
\text { MPS } 1(1: 30,000)\end{array}$ & $\begin{array}{l}\text { Fabry }(0.01 \%) \\
\text { Pompe }(0.012 \%) \\
\text { MPS } 1(0.006 \%)\end{array}$ \\
\hline New York State ${ }^{68}$ & 2006 & $\mathrm{MS} / \mathrm{MS}$ & 550,000 & Krabbe $(1: 50,000)$ & $\mathrm{N} / \mathrm{A}$ \\
\hline Austria $^{64}$ & 2010 & LC-MS/MS & 34,736 & $\begin{array}{l}\text { Fabry }(1: 3,859) \\
\text { Gaucher }(1: 17,368) \\
\text { Pompe }(1: 8,684) \\
\text { Niemann-Pick A/B (N/A) }\end{array}$ & $\begin{array}{l}\text { Fabry }(0.055 \%) \\
\text { Gaucher }(0.006 \%) \\
\text { Pompe }(0.003 \%) \\
\text { Niemann-Pick A/B }(0.003 \%)\end{array}$ \\
\hline $\operatorname{Japan}^{67}$ & 2013 & $\begin{array}{l}\text { Fluorometric } \\
\text { enzyme assay }\end{array}$ & 21,170 & Fabry $(1: 7,057)$ & Fabry $(0.018 \%)$ \\
\hline Italy ${ }^{65}$ & 2003 & $\begin{array}{l}\text { Fluorometric } \\
\text { enzyme assay }\end{array}$ & 37,104 & Fabry $(1: 3,100)$ & Fabry (0.078\%) \\
\hline Hungary $^{66}$ & 2012 & $\mathrm{MS} / \mathrm{MS}$ & 40,024 & $\begin{array}{l}\text { Fabry }(1: 13,341) \\
\text { Gaucher }(1: 13,341) \\
\text { Pompe }(1: 4,447) \\
\text { Niemann-Pick A/B }(1: 20,012)\end{array}$ & $\begin{array}{l}\text { Fabry }(0.080 \%) \\
\text { Gaucher }(0.035 \%) \\
\text { Pompe }(0.14 \%) \\
\text { Niemann-Pick A/B }(0.007 \%)\end{array}$ \\
\hline Taiwan $^{61}$ & 2012 & $\begin{array}{l}\text { Modified Fluorometric } \\
\text { enzyme assay }\end{array}$ & 473,738 & Pompe $(1: 16,900)$ & Pompe (0.47\%) \\
\hline Illinois ${ }^{71}$ & 2011 & $\begin{array}{l}\text { Digital microfluidic } \\
\text { enzyme assay }\end{array}$ & 8,012 & $\begin{array}{l}\text { Fabry }(1: 1,144) \\
\text { Gaucher }(1: 4,006)\end{array}$ & $\begin{array}{l}\text { Fabry }(0.05 \%) \\
\text { Gaucher }(0.25 \%) \\
\text { Pompe }(0.025 \%)\end{array}$ \\
\hline
\end{tabular}

Abbreviations: LS-MS/MS, liquid chromatography mass spectrometry; MS/MS, tandem mass spectrometry; N/A, (data) not available; NBS, newborn screening. 
not always straightforward. In addition, assay reagents are not always available from generic vendors, potentially hampering assay development. There have also been concerns surrounding the nonspecificity of fluorometric assays for detection of Niemann-Pick A/B disease. The incorporation of a fluorophore into substrates for acid sphingomyelinase (ASM) has led to several false-negative results being reported in patients with a common mutation in the ASM gene (p.Gln292Lys). ${ }^{38,39}$

\section{Enzyme Activity Determination Using MS/MS}

The development of MS/MS methods for use with DBS has transformed high-throughput screening for IEM. ${ }^{10,40}$ MS/MS combines the advantages of improved selectivity and excellent sensitivity with multiplexing capability. The first MS/MS methods for LSDs including enzyme-specific substrates and internal standards were developed by Gelb and coworkers, who reported a single multiplexing MS/MS assay for Pompe, Fabry, Gaucher, Niemann-Pick A/B, and Krabbe diseases, ${ }^{41,42}$ and later for MPS I and II. $^{43,44}$ In addition to DBS proficiency testing materials, LSD assay cocktail preparations containing substrates and internal standards are distributed by the Newborn Screening Quality Assurance Program at the Centers for Disease Control and Prevention (CDC). ${ }^{45,46}$ These developments ultimately led to robust, multiplexing MS/MS protocols for LSD testing using commercially available substrates and validated control materials.

The first MS/MS assays (known collectively as flow-injection MS/MS assays) were largely limited by the "pre-MS/MS" component of the method. The mass spectrometer measures enzymatic reaction products that can be readily multiplexed in rapidly occurring simultaneous experiments. Sample throughput is, however, limited by complicated, time-consuming, and labor-intensive sample preparative steps prior to injection onto the MS/MS. First, enzymatic reactions require long incubation periods (typically $\sim 20$ hours at $37^{\circ} \mathrm{C}$ ) and unique buffer cocktails optimized for each individual reaction. Second, the components of the reaction buffers are incompatible with MS/MS and require intensive clean-up procedures using a combination of liquid/liquid and solid-phase extraction (SPE) steps. Several groups have taken various approaches to help address these issues. Combined enzymatic assays were subsequently developed for LSD assay panels using a common reaction buffer for all enzymes, as described for the triplex assay for Fabry, Pompe diseases, and MPS I. ${ }^{47}$ Others have investigated the necessity of long incubation periods for enzymatic reactions. A short-incubation protocol was proposed by Mechler et al whereby they developed a 5-plex LSD assay with 3-hour incubations followed by detection of enzymatic products by MS/MS. ${ }^{48}$ Assay performance was deemed acceptable for imprecision compared with standard 20-hour incubation protocols. Further attempts to automate the sample clean-up process have resulted in the development of liquid chromatography tandem mass spectrometry (LC-MS/MS) methods. Multidimensional chromatographic methods using online trapping columns and valve-switching apparatus have been described by several groups. ${ }^{49-51}$ The LC-MS/MS approach was further developed by incorporating a universal assay incubation buffer for triplex (Pompe, Fabry diseases, and MPS I) and 9-plex assays. ${ }^{52,53}$
Recently, there has been much debate regarding the use of flow-injection MS/MS versus LC-MS/MS methods for incoming NBS programs. There are concerns over the added costs and complexity associated with the introduction of chromatography steps in large population screening methods. The group at the University of Washington in collaboration with PerkinElmer Corp has developed a novel flow injection MS/ MS method using a simple liquid-liquid extraction step. This method uses a universal substrate/internal standard reaction mix for the 6-plex assay (Pompe, Gaucher, Fabry, NiemannPick A/B, Krabbe diseases, and MPS I) and is commercially available from PerkinElmer Corp. (Indianapolis, IN) for adoption by screening laboratories. It has been suggested that this latest version of the MS/MS assay outperforms earlier versions, and also the microfluidics assay in terms of falsepositive rates. In addition, the "pre-MS/MS" phase of the new MS/MS assay is reported to be more streamlined compared with previous versions. ${ }^{37}$

\section{Immunoquantification Assays}

In most LSDs, pathogenic mutations lead to a decreased amount of protein and subsequent reduced enzyme activity. This observation was exploited in the development of immunoquantification assays. ${ }^{54}$ Enhanced performance immune quantification assays using immunocapture microbead technology have been developed in multiplex format for up to 11 LSDs for use with DBS. ${ }^{55}$ Trials using this approach have demonstrated its usefulness for NBS in the identification of patients with Pompe, Fabry, Gaucher diseases, and MPS II. ${ }^{56-59}$ Variations of the immunoquantification assay incorporating additional biomarkers such as $\alpha-N$-acetylglucosaminidase and chitotriosidase may increase the diagnostic efficiency of the method for Pompe and Gaucher diseases. ${ }^{60}$

\section{Newborn Screening Initiatives}

\section{Global Pilot Programs}

Most of the available information on NBS for LSDs has been gained from pilot studies. At least seven LSDs have been proposed for NBS including Pompe, Gaucher, Fabry, NiemannPick A/B, Krabbe diseases, and MPS I. ${ }^{23}$ Several countries around the world and several states within the United States have already shared data and reported their experiences (-Table 2).

\section{Taiwan}

NBS for Pompe disease has been performed across multiple centers in Taiwan since 2005 because of the high prevalence of the condition in the population and availability of treatment. ${ }^{33}$ In a recent large-scale study, NBS was performed on 473,738 patients on samples collected at age 48 to 72 hours. ${ }^{61}$ As a first-line screening test, modified fluorometric enzyme assays were used to measure two enzymes: acid $\alpha$-glucosidase (GAA) activity at $\mathrm{pH} 3.8$ in the presence of acarbose and neutral $\alpha$-glucosidase (NAG) activity at $\mathrm{pH} 7.0$ in the absence of acarbose. A final calculation of specific activity was determined using the neutral to acid ratio (NAG/GAA). A cutoff for NAG/GAA 100 or greater was designated screen positive and 
reflexed to confirmatory testing. Using these screening criteria, 31 newborns exceeded the cutoff, of which there were 5 confirmed cases of classic infantile Pompe disease and 19 cases of late-onset Pompe (including nonclassic disease). A third assay measuring total GAA (tGAA) activity at pH 3.8 without acarbose was performed as a second-line test for samples that had an equivocal first-line result (NAG/GAA $\geq 30$ to $<100$ ). Screen-positive results after second-line testing led to referral for confirmatory testing. Of 2,210 samples submitted for second-line testing, 219 retested positive. Confirmatory molecular analysis revealed two additional late-onset Pompe disease patients.

The high prevalence of pseudodeficiency alleles in Taiwan necessitates the need for more complex screening approaches using second-tier analyses. For instance, the frequency of the pseudodeficiency allele p.G576S in the Taiwanese population is reported to be as high as $14.5 \%$, which makes it more difficult to detect Pompe disease by enzyme activity determination alone. By using conventional fluorometric enzyme assays, measurement of the NAG/GAA ratio is essential to avoid a high false positive rate. ${ }^{62}$

In another NBS pilot program, screening for Pompe, Fabry, Gaucher diseases, and MPS I disorders was performed using both fluorometric and flow-injection MS/MS methods. ${ }^{63}$ MS/MS is particularly advantageous for detection of Pompe disease in the Taiwanese population as it is not necessary to measure both acid and NAG activities. Rather, a single assay may be performed using substrates of different masses that can be selected apart. In the Pompe program, a total of 191,786 newborns were screened using a screen-positive GAA cutoff value of $1.6 \mu \mathrm{mol} / \mathrm{L} / \mathrm{h}$. A total of nine cases were referred to hospitals directly with GAA values below the "critical" cutoff value of $0.20 \mu \mathrm{mol} / \mathrm{L} / \mathrm{h}$. Four of these cases were confirmed to have infantile Pompe disease and three were designated late-onset Pompe disease. Following firstline screening, 874 newborns were re-called for second-line testing, of which 225 were referred with decreased enzyme activity using a reduced cutoff value for GAA $(1.0 \mu \mathrm{mol} / \mathrm{L} / \mathrm{h})$ activity. Of these referrals, only 16 cases were confirmed by GAA mutation analysis to have Pompe disease (5 infantile Pompe and 11 classified as late-onset Pompe disease). The high false-positive rates observed are likely due to the high frequency of the pseudodeficiency allele in the population. However, the authors suggest that there was a significant reduction in the false-positive rate observed for Pompe screening when using MS/MS compared with the previously used fluorometric enzyme assay. In the Fabry study, 191,767 newborns were screened using a positive GLA cutoff value of $1.5 \mathrm{umol} / \mathrm{L} / \mathrm{h}$. After first-tier testing, 379 newborns had equivocal results and were re-called. After second-tier screening, there were approximately 79 suspected cases with reduced enzyme activity, out of which 64 newborns were confirmed to have Fabry mutations by molecular analysis. In the Gaucher study, 103,134 newborns were screened using a positive cutoff value of $7.5 \mathrm{umol} / \mathrm{L} / \mathrm{h}$. After the firsttier screen, approximately 141 newborns had equivocal results and were re-called for second-line testing, after which 5 cases were referred for low activity. Three cases were eventually confirmed as having at least one ABG gene mutation. In the MPS I study, a total of 60,473 newborns were screened using a positive cutoff value of $3 \mu \mathrm{mol} / \mathrm{L} / \mathrm{h}$. Only two confirmed positive cases of MPS I were detected and confirmed.

\section{Austria}

In 2010, a large-scale pilot study was performed as part of the national Austrian NBS program using a multiplex screening assay for Pompe, Gaucher, Fabry, and Niemann-Pick A/B diseases. ${ }^{64}$ Screening was performed on 34,736 newborns using LC-MS/MS. Screen cutoff values for normal activity were set according to the 0.1 th percentile of 5,000 samples as follows: Gaucher, $4.0 \mu \mathrm{mol} / \mathrm{h} / \mathrm{L}$; Pompe, $2.0 \mu \mathrm{mol} / \mathrm{h} / \mathrm{L}$; Fabry, $2.8 \mu \mathrm{mol} / \mathrm{h} / \mathrm{L} ;$ Niemann-Pick A/B, $1.3 \mu \mathrm{mol} / \mathrm{h} / \mathrm{L}$. First-line screening identified 124 samples with low activity for all four enzymes: $\beta$-glucocerebrosidase (ABG) 29; GAA 25; $\alpha$ galactosidase (GLA) 42; ASM 28. After retesting, 38 samples screened positive, of which 15 cases were confirmed by molecular analysis as having pathogenic mutations. This translates to a positive predictive value of between 32 and $80 \%$ for all disorders. Of the 15 confirmed cases, the authors were unable to find a significant correlation between low enzyme activity and mutation. They also reported that $75 \%$ of mutations were associated with a mild phenotype characterized by late-onset disease. The overall incidence observed in this study was unexpectedly high, at 1 in 2,315 live births for all disorders.

\section{Italy}

Spada et al reported the screening of 37,104 male newborns from 2003 to 2005 for Fabry disease using fluorometric enzyme assay determination of GLA activity. ${ }^{65}$ First-line testing identified 41 neonates with decreased GLA activity using a positive screen cutoff value of $2.5 \mathrm{U} / \mathrm{mL}$ or less. This number was reduced to 12 neonates following molecular confirmation, only one of which possessed a known pathogenic mutation causing the classic phenotype. This translates to a population incidence of 1 in 37,000 males for classic Fabry disease, consistent with previously published estimates. The remaining 11 newborns had both known pathogenic and novel mutations associated with the lateronset phenotype. When known pathogenic and novel GLA mutations were combined, the study revealed an incidence of 1 in 3,100. This represented a much higher incidence of later-onset Fabry disease than expected, compared with the classic phenotype.

\section{Hungary}

Wittmann et al reported results from the Hungarian program. ${ }^{66}$ NBS was performed on 40,024 newborns for Gaucher, Pompe, Fabry, and Niemann-Pick A/B disorders using an MS/MS method. In an attempt to maintain a low re-call rate, screen-positive cutoff values were fixed between the lower 0.25th and 0.5th percentile of distribution of measured enzyme activities as follows: ABG $3.5 \mu \mathrm{mol} / \mathrm{L} / \mathrm{h}$; GAA $3.0 \mu \mathrm{mol} / \mathrm{L} / \mathrm{h} ;$ GLA $2.5 \mu \mathrm{mol} / \mathrm{L} / \mathrm{h}$; ASM $2.0 \mu \mathrm{mol} / \mathrm{L} / \mathrm{h}$. A total of 642 samples were positive for low enzyme activity: 
141 for ABG (Gaucher diseases), 163 for GAA (Pompe diseases), 224 for GLA (Fabry diseases) and 114 for ASM (Niemann-Pick A/B). Following second-line testing on initial screen positives, 120 total samples were subjected to molecular analysis: 3 patients were confirmed as having Gaucher disease, 9 confirmed cases of Pompe disease (with a further 2 unclear), 3 confirmed cases of Fabry disease (with a further 2 unclear), and 2 confirmed cases of Niemann-Pick A/B. The resulting prevalence of each disorder was as follows: Gaucher disease $1: 13,341$; Pompe disease $1: 4,447$ to $1: 20,012$; Fabry disease $1: 13,341$; Niemann Pick A/B 1:20,012 to $1: 40,024$. The overall prevalence of all four combined LSDs was between 1 in 2,354 and 1 in 4,447 live births. The authors noted that the screen-positive cutoff values used in this study were at the limit of detection for Pompe and Gaucher diseases, and that further reduction would almost certainly have resulted in missed cases.

\section{Japan}

An NBS pilot study was conducted for Fabry disease in Japan from 2007 to $2010 .^{67}$ Over a 37-month period, a total of 21,170 newborns were enrolled (approximately equal numbers of males and females) and screened using a fluorometric enzyme assay with a screen-positive cutoff value for GLA activity of less than 20 AgalU. Using these criteria, seven newborns (five males and two females) tested positive for low GLA activity in DBS samples, four of which exhibited decreased GLA activities when assayed in leukocytes. Subsequent molecular analysis confirmed known pathogenic mutations in the GLA gene for three screen-positive newborns. The calculated prevalence of Fabry disease in this population was 1 in 7,057, based on confirmed cases with pathogenic mutations. The observed prevalence, although much higher than expected, was consistent with equivalent data from other pilot screening programs.

\section{Newborn Screening within the United States}

Several states in the United States have opted to expand NBS to include LSDs. The New York State and Missouri NBS programs were the first to offer state-wide screening of any LSDs in 2006 and 2013, respectively. Pilot programs have also been performed in Washington State. Several other states have since passed legislation requiring mandatory screening for LSDs, including Illinois, New Mexico, and New Jersey.

\section{New York State}

The New York State NBS program for Krabbe disease was implemented in 2006. Duffner et al reported the findings from a pilot study where they screened approximately 550,000 newborns for Krabbe disease over a 2-year period using flow-injection MS/MS. ${ }^{68}$ Using a screen-positive cutoff value based on a percentage of the daily mean galactocerebrosidase (GALC) activity, they identified 10 newborns with enzyme activities in the high- or moderate-risk categories ( 4 high-risk and 6 moderate-risk). Of the four high-risk newborns, two had mutations associated with early infantile Krabbe disease and exhibited neurologic testing results consistent with established diagnostic criteria. The other two high-risk newborns were neurologically and developmentally normal. Of the six moderaterisk newborns, all were reported to be developing normally. The New York State experience has challenged previous knowledge regarding both disease prevalence and disease phenotype. The difference between the published reported incidence of Krabbe disease ( $\sim 1$ in 100,000 live births) and the observed incidence ( 1 in 50,000 newborns, based on screen positives with high or moderate risk for disease) was a noteworthy finding. In addition, it was expected that most patients would be diagnosed with the early infantile Krabbe phenotype. However, in this study, only 20\% of newborns in the high- or moderate-risk categories for disease were diagnosed with the early phenotype. In fact, during the first 8 years of Krabbe screening, the early-onset phenotype was detected in only 1 in 400,000 newborns. The authors suggest that this finding might represent a significant underestimation of later-onset Krabbe diagnoses in the absence of NBS programs.

\section{Missouri}

In 2013, the Missouri State Public Health Laboratory mandated NBS for LSDs. Population screening is currently ongoing for Pompe, Fabry, Gaucher, MPS I, and Krabbe diseases (Krabbe disease analysis was outsourced to the New York State program). The Missouri program was the first state program to perform a comprehensive population pilot screening study with follow-up care for each of the four conditions. It was also the first state program to use a multiplexing digital microfluidic fluorometric enzymatic assay. Hopkins et al reported the findings from the first 6 months of screening on 43,701 newborns. ${ }^{69}$ Enzyme activity screen-positive cutoff values chosen were as follows: GLA (Fabry disease), $5.5 \mu \mathrm{mol} / \mathrm{L} / \mathrm{h}$; GAA (Pompe disease), 8.0 $\mu \mathrm{mol} / \mathrm{L} / \mathrm{h} ; \mathrm{ABG}$ (Gaucher disease), $4.5 \mu \mathrm{mol} / \mathrm{L} / \mathrm{h}$; IDUA (MPS I), $4.0 \mu \mathrm{mol} / \mathrm{L} / \mathrm{h}$. Using these criteria, 27 newborns were identified and confirmed as having a disorder (15 Fabry disease, 8 Pompe disease, 1 Gaucher disease, and 3 MPS I). In a similar trend to that previously reported in several other NBS programs, there was a marked difference between the expected and observed prevalence of each disorder. For Fabry disease, the number of confirmed cases translated to an incidence of 1 in 2,913, compared with the published estimated incidence of 1 in 40,000. Similar differences were observed for Pompe disease (observed: 1 in 5,463; expected: 1 in 40,000), Gaucher disease (observed: 1 in 43,701; expected: 1 in 50,000), and MPS I (observed: 1 in 14,567; expected: 1 in 100,000). The Fabry data obtained from this study are consistent with other NBS program pilot studies. However, there was significant variation between studies in the detection rates observed for Pompe and Gaucher diseases. The authors also suggest that the false positives obtained in the study were probably due to the relatively conservative screen-positive cutoff values used, and argue that some of these cases may in fact be carriers for the condition. 


\section{Washington State}

In the Washington State pilot program, screening was performed at the University of Washington on 111,544 newborns using flow-injection MS/MS for Fabry disease, Pompe disease, and MPS I. ${ }^{70}$ Arbitrary enzyme activity cutoffs were assigned at $19 \%$ or less of the daily mean value for GLA $(1.91 \mathrm{umol} / \mathrm{h} / \mathrm{L}), 15 \%$ or less of the daily mean value for GAA $(2.60 \mathrm{umol} / \mathrm{h} / \mathrm{L})$, and $32 \%$ or less of the daily mean value for IDUA $(1.15 \mathrm{umol} / \mathrm{h} / \mathrm{L})$. Screen-positive cases were confirmed by DNA sequencing. Using these criteria, the estimated prevalence of Fabry disease was 1 in 7,800 males; Pompe disease, 1 in 27,800 newborns; and for MPS I, 1 in 35,500 newborns. The combined prevalence for all three disorders was 1 in 7,700 newborns. The falsepositive rates for each disorder were also deemed sufficiently low for this study. As of June 2014, the Washington state NBS laboratory have been conducting a pilot study using the new flow-injection MS/MS commercial 6-plexassay provided by PerkinElmer. In a recent review by Gelb et al, the authors reported a very low number of screen positives using the new kit method. ${ }^{37}$ This is particularly encouraging for laboratories operating MS/MS methods using CDC-distributed reagents, since the $\mathrm{CDC}$ are scheduled to discontinue the distribution of substrate kits by the end of 2015 .

\section{Illinois}

A pilot NBS program for LSDs was performed in the State of Illinois in 2011, where at total of 8,012 newborns were screened for Pompe, Fabry, and Gaucher diseases using the digital microfluidic fluorometric enzyme assay platform..$^{71}$ Two positive cases were initially identified for Pompe disease via screening, but they were normal on confirmatory testing. For Fabry disease screening, 11 newborns were identified ( 8 males and 3 females) with 7 confirmed on confirmatory testing. Gaucher disease screening revealed 22 positive cases, of which 2 cases were subsequently confirmed. The pilot project was stopped because of technical issues involving the assay method. A second pilot program using MS/MS was proposed for 2013.

\section{Ethical Considerations of Newborn Screening}

As NBS for LSDs evolves from pilot studies to whole-population programs, the ethical considerations associated with screening for these disorders have been subject to considerable debate. Advocates of NBS have pointed toward the mounting evidence that early diagnosis and treatment of many LSDs are strongly associated with better clinical outcomes. Skeptics of NBS have countered that there is still much uncertainty surrounding whole-population screening for LSDs, including the inability to predict phenotype and the lack of consensus about when to initiate treatment for most of the conditions. Critics of NBS also argue that is not just a panel of screening tests, but rather a multifactorial care pathway involving parental education, follow-up, diagnosis, treatment and management, and program evaluation. All of these components must be in place and fully functional to reap the benefits of screening. ${ }^{72}$ There is also concern that state mandates for NBS is being driven by powerful lobbyist groups and parent advocates, bypassing state public health departments and advisory committees. ${ }^{73}$

\section{Ethical Approval}

In a review from Dees and Kwon reviewing the lessons learned from the New York State pilot screening program for Krabbe disease, they concluded that Krabbe screening should only be continued as a research project that requires the informed consent of parents prior to testing. ${ }^{74}$ During the pilot study, informed parental consent was required, as was institutional review board (IRB) approval, consistent with research protocols. However, New York State later mandated NBS for Krabbe disease without seeking IRB approval or a requirement for consent. ${ }^{75}$ Some commentators suggest that perhaps a two-tiered approach to NBS should be adopted, involving mandatory screening for conditions that meet the public health screening criteria and voluntary screening for other conditions, requiring informed consent. ${ }^{74}$

\section{Late-Onset Phenotypes}

One of the main controversies associated with NBS for several LSDs is the identification of infants with anticipated lateonset disorders. This has the undesirable effect of creating a population of asymptomatic children who are essentially "patients in waiting." ${ }^{76}$ It also violates most international pediatric genetic ethics guidelines that stipulate that screening is not advised for late-onset conditions. ${ }^{77}$ The New York State NBS program for Krabbe disease identified a large number of children as being moderate to high risk requiring aggressive clinical follow-up. There have been questions raised regarding the psychosocial impact that such aggressive clinical follow-up may cause to these children. There is also debate as to whether or not the level of GALC activity or the genotype can accurately predict whether the child will develop early infantile-onset, adolescent-, or adult-onset phenotype. This has serious implications regarding effective treatment of the early infantile phenotype. There are similar concerns regarding later-onset phenotypes for Fabry disease. The question of when to screen patients for the late-onset disease is still under debate, particularly considering the relatively high incidence of this form of the disorder.

\section{Counseling}

There have always been concerns whether newborns testing positive in newborn mass screening programs are given a presymptomatic diagnosis by genetic testing. Ideally, such testing should only be performed after providing parents with sufficient counseling to make an informed decision. This should include adequate education on the symptoms and disease progression, and future medical management and risk of recurrence. For X-linked disorders such as Fabry disease, counseling may create a burden to mothers and may adversely affect family relationships.

\section{Conclusion}

The imminent widespread introduction of NBS for LSDs represents an intriguing new development in preventive medicine. 
Despite reservations surrounding the identification of late-onset phenotypes for disorders such as early-onset Pompe disease, Krabbe disease, and MPS I, it is clear that early, presymptomatic intervention is imperative to help prevent severe, life-threatening disabilities. Over the past decade, there have been significant developments in large-scale biochemical screening methods for LSDs. Cost-effective, high-throughput assays are now available in standardized format for incoming NBS programs. However, biochemical methods have their limitations, and molecular analysis is still required for confirmatory analyses. At present, molecular testing is not being used as the primary screening or diagnostic method for LSDs. However, this may change in the near future, as newer versions of next-generation sequencing (NGS) platforms become more rapid, reliable, and cost-effective. Even if this is technically possible, the challenges associated with incorporating NGS in NBS programs have been widely debated. ${ }^{78}$

\section{References}

1 Boyle CA, Bocchini JA Jr, Kelly J. Reflections on 50 years of newborn screening. Pediatrics 2014;133(6):961-963

2 Guthrie R, Susi A. A simple phenylalanine method for detecting phenylketonuria in large populations of newborn infants. Pediatrics 1963;32:338-343

3 Guthrie R. Screening for "inborn errors of metabolism" in the newborn infant: a multiple test program. Birth Defects Orig Artic Ser 1968;4:92-96

4 Wilson JMG, Jungner G. Principles and Practice of Screening for Disease. Geneva: World Health Organization; 1968. Available at: http://whqlibdoc.who.int/php/WHO_PHP_34.pdf

5 Dussault JH, Coulombe P, Laberge C, Letarte J, Guyda H, Khoury K. Preliminary report on a mass screening program for neonatal hypothyroidism. J Pediatr 1975;86(5):670-674

6 Garrick MD, Dembure P, Guthrie R. Sickle-cell anemia and other hemoglobinopathies. Procedures and strategy for screening employing spots of blood on filter paper as specimens. N Engl J Med 1973;288(24):1265-1268

7 Pang S, Hotchkiss J, Drash AL, Levine LS, New MI. Microfilter paper method for 17 alpha-hydroxyprogesterone radioimmunoassay: its application for rapid screening for congenital adrenal hyperplasia. J Clin Endocrinol Metab 1977;45(5):1003-1008

8 Heard GS, Secor McVoy JR, Wolf B. A screening method for biotinidase deficiency in newborns. Clin Chem 1984;30(1):125-127

9 Whitehouse CM, Dreyer RN, Yamashita M, Fenn JB. Electrospray interface for liquid chromatographs and mass spectrometers. Anal Chem 1985;57(3):675-679

10 Millington DS, Kodo N, Norwood DL, Roe CR. Tandem mass spectrometry: a new method for acylcarnitine profiling with potential for neonatal screening for inborn errors of metabolism. J Inherit Metab Dis 1990;13(3):321-324

11 Levy HL. Newborn screening by tandem mass spectrometry: a new era. Clin Chem 1998;44(12):2401-2402

12 Chace DH, Millington DS, Terada N, Kahler SG, Roe CR, Hofman LF. Rapid diagnosis of phenylketonuria by quantitative analysis for phenylalanine and tyrosine in neonatal blood spots by tandem mass spectrometry. Clin Chem 1993;39(1):66-71

13 Chace DH, Hillman SL, Millington DS, Kahler SG, Roe CR, Naylor EW. Rapid diagnosis of maple syrup urine disease in blood spots from newborns by tandem mass spectrometry. Clin Chem 1995; 41(1):62-68

14 Chace DH, Hillman SL, Millington DS, Kahler SG, Adam BW, Levy HL. Rapid diagnosis of homocystinuria and other hypermethioninemias from newborns' blood spots by tandem mass spectrometry. Clin Chem 1996;42(3):349-355
15 Pitt JJ. Newborn screening. Clin Biochem Rev 2010;31(2):57-68

16 Zytkovicz TH, Fitzgerald EF, Marsden D, et al. Tandem mass spectrometric analysis for amino, organic, and fatty acid disorders in newborn dried blood spots: a two-year summary from the New England Newborn Screening Program. Clin Chem 2001;47(11): 1945-1955

17 Wilcken B, Wiley V, Hammond J, Carpenter K. Screening newborns for inborn errors of metabolism by tandem mass spectrometry. N Engl J Med 2003;348(23):2304-2312

18 Levy HL. Newborn screening conditions: What we know, what we do not know, and how we will know it. Genet Med 2010;12(12, Suppl)S213-S214

19 Watson MS, Mann MY, Lloyd-Puryear MA, Rinaldo P, Howell RR. Newborn screening: toward a uniform screening panel and system. Genet Med 2006;8(Suppl 1):1S-252S

20 http://www.hrsa.gov/advisorycommittees/mchbadvisory/heritabledisorders/about/index.html. Accessed April 20, 2015

21 Kemper AR, Knapp AA, Green NS, Comeau AM, Metterville DR, Perrin JM. Weighing the evidence for newborn screening for earlyinfantile Krabbe disease. Genet Med 2010;12(9):539-543

22 Futerman AH, van Meer G. The cell biology of lysosomal storage disorders. Nat Rev Mol Cell Biol 2004;5(7):554-565

23 Marsden D, Levy H. Newborn screening of lysosomal storage disorders. Clin Chem 2010;56(7):1071-1079

24 Staretz-Chacham O, Lang TC, LaMarca ME, Krasnewich D, Sidransky E. Lysosomal storage disorders in the newborn. Pediatrics 2009;123(4):1191-1207

25 Hollak CE, Wijburg FA. Treatment of lysosomal storage disorders: successes and challenges. J Inherit Metab Dis 2014;37(4):587-598

26 Chamoles NA, Blanco M, Gaggioli D. Fabry disease: enzymatic diagnosis in dried blood spots on filter paper. Clin Chim Acta 2001; 308(1-2):195-196

27 Chamoles NA, Blanco M, Gaggioli D. Diagnosis of alpha-L-iduronidase deficiency in dried blood spots on filter paper: the possibility of newborn diagnosis. Clin Chem 2001;47(4):780-781

28 Chamoles NA, Blanco M, Gaggioli D, Casentini C. Tay-Sachs and Sandhoff diseases: enzymatic diagnosis in dried blood spots on filter paper: retrospective diagnoses in newborn-screening cards. Clin Chim Acta 2002;318(1-2):133-137

29 Chamoles NA, Blanco M, Gaggioli D, Casentini C. Gaucher and Niemann-Pick diseases-enzymatic diagnosis in dried blood spots on filter paper: retrospective diagnoses in newborn-screening cards. Clin Chim Acta 2002;317(1-2):191-197

30 Chamoles NA, Blanco MB, Gaggioli D, Casentini C. Hurler-like phenotype: enzymatic diagnosis in dried blood spots on filter paper. Clin Chem 2001;47(12):2098-2102

31 Chamoles NA, Niizawa G, Blanco M, Gaggioli D, Casentini C. Glycogen storage disease type II: enzymatic screening in dried blood spots on filter paper. Clin Chim Acta 2004;347(1-2):97-102

32 Civallero G, Michelin K, de Mari J, et al. Twelve different enzyme assays on dried-blood filter paper samples for detection of patients with selected inherited lysosomal storage diseases. Clin Chim Acta 2006;372(1-2):98-102

33 Chien YH, Chiang SC, Zhang XK, et al. Early detection of Pompe disease by newborn screening is feasible: results from the Taiwan screening program. Pediatrics 2008;122(1):e39-e45

34 Sista RS, Eckhardt AE, Wang T, et al. Digital microfluidic platform for multiplexing enzyme assays: implications for lysosomal storage disease screening in newborns. Clin Chem 2011;57(10): 1444-1451

35 Sista R, Eckhardt AE, Wang T, Séllos-Moura M, Pamula VK. Rapid, single-step assay for Hunter syndrome in dried blood spots using digital microfluidics. Clin Chim Acta 2011;412(19-20):1895-1897

36 Sista RS, Wang T, Wu N, et al. Multiplex newborn screening for Pompe, Fabry, Hunter, Gaucher, and Hurler diseases using a digital microfluidic platform. Clin Chim Acta 2013;424:12-18

37 Gelb MH, Scott CR, Turecek F. Newborn screening for lysosomal storage diseases. Clin Chem 2015;61(2):335-346 
38 van Diggelen OP, Voznyi YV, Keulemans JL, et al. A new fluorimetric enzyme assay for the diagnosis of Niemann-Pick A/B, with specificity of natural sphingomyelinase substrate. J Inherit Metab Dis 2005;28(5):733-741

39 Harzer K, Rolfs A, Bauer P, et al. Niemann-Pick disease type A and B are clinically but also enzymatically heterogeneous: pitfall in the laboratory diagnosis of sphingomyelinase deficiency associated with the mutation Q292 K. Neuropediatrics 2003;34(6):301-306

40 Chace DH, Kalas TA, Naylor EW. Use of tandem mass spectrometry for multianalyte screening of dried blood specimens from newborns. Clin Chem 2003;49(11):1797-1817

41 Li Y, Brockmann K, Turecek F, Scott CR, Gelb MH. Tandem mass spectrometry for the direct assay of enzymes in dried blood spots: application to newborn screening for Krabbe disease. Clin Chem 2004;50(3):638-640

$42 \mathrm{Li}$ Y, Scott CR, Chamoles NA, et al. Direct multiplex assay of lysosomal enzymes in dried blood spots for newborn screening. Clin Chem 2004;50(10):1785-1796

43 Blanchard S, Sadilek M, Scott CR, Turecek F, Gelb MH. Tandem mass spectrometry for the direct assay of lysosomal enzymes in dried blood spots: application to screening newborns for mucopolysaccharidosis I. Clin Chem 2008;54(12):2067-2070

44 Wolfe BJ, Blanchard S, Sadilek M, Scott CR, Turecek F, Gelb MH. Tandem mass spectrometry for the direct assay of lysosomal enzymes in dried blood spots: application to screening newborns for mucopolysaccharidosis II (Hunter syndrome). Anal Chem 2011;83(3):1152-1156

45 Zhang XK, Elbin CS, Chuang WL, et al. Multiplex enzyme assay screening of dried blood spots for lysosomal storage disorders by using tandem mass spectrometry. Clin Chem 2008;54(10):1725-1728

46 De Jesus VR, Zhang XK, Keutzer J, et al. Development and evaluation of quality control dried blood spot materials in newborn screening for lysosomal storage disorders. Clin Chem 2009;55(1):158-164

47 Duffey TA, Bellamy G, Elliott S, et al. A tandem mass spectrometry triplex assay for the detection of Fabry, Pompe, and mucopolysaccharidosis-I (Hurler). Clin Chem 2010;56(12):1854-1861

48 Mechtler TP, Metz TF, Müller HG, et al. Short-incubation mass spectrometry assay for lysosomal storage disorders in newborn and high-risk population screening. J Chromatogr B Analyt Technol Biomed Life Sci 2012;908:9-17

49 la Marca G, Casetta B, Malvagia S, Guerrini R, Zammarchi E. New strategy for the screening of lysosomal storage disorders: the use of the online trapping-and-cleanup liquid chromatography/mass spectrometry. Anal Chem 2009;81(15):6113-6121

50 Kasper DC, Herman J, De Jesus VR, Mechtler TP, Metz TF, Shushan B. The application of multiplexed, multi-dimensional ultra-high-performance liquid chromatography/tandem mass spectrometry to the highthroughput screening of lysosomal storage disorders in newborn dried bloodspots. Rapid Commun Mass Spectrom 2010;24(7):986-994

51 Metz TF, Mechtler TP, Orsini JJ, et al. Simplified newborn screening protocol for lysosomal storage disorders. Clin Chem 2011;57(9): 1286-1294

52 Spáčil Z, Elliott S, Reeber SL, Gelb MH, Scott CR, Tureček F. Comparative triplex tandem mass spectrometry assays of lysosomal enzyme activities in dried blood spots using fast liquid chromatography: application to newborn screening of Pompe, Fabry, and Hurler diseases. Anal Chem 2011;83(12):4822-4828

53 Spacil Z, Tatipaka H, Barcenas M, Scott CR, Turecek F, Gelb MH. High-throughput assay of 9 lysosomal enzymes for newborn screening. Clin Chem 2013;59(3):502-511

54 Meikle PJ, Grasby DJ, Dean CJ, et al. Newborn screening for lysosomal storage disorders. Mol Genet Metab 2006;88(4):307-314

55 Parkinson-Lawrence E, Fuller M, Hopwood JJ, Meikle PJ, Brooks DA. Immunochemistry of lysosomal storage disorders. Clin Chem 2006;52(9):1660-1668

56 Umapathysivam K, Whittle AM, Ranieri E, et al. Determination of acid alpha-glucosidase protein: evaluation as a screening marker for Pompe disease and other lysosomal storage disorders. Clin Chem 2000;46(9):1318-1325

57 Fuller M, Lovejoy M, Brooks DA, Harkin ML, Hopwood JJ, Meikle PJ. Immunoquantification of alpha-galactosidase: evaluation for the diagnosis of Fabry disease. Clin Chem 2004;50(11):1979-1985

58 Fuller M, Lovejoy M, Hopwood JJ, Meikle PJ. Immunoquantification of beta-glucosidase: diagnosis and prediction of severity in Gaucher disease. Clin Chem 2005;51(11):2200-2202

59 Dean CJ, Bockmann MR, Hopwood JJ, Brooks DA, Meikle PJ. Detection of mucopolysaccharidosis type II by measurement of iduronate-2-sulfatase in dried blood spots and plasma samples. Clin Chem 2006;52(4):643-649

60 Fuller M, Tucker JN, Lang DL, et al. Screening patients referred to a metabolic clinic for lysosomal storage disorders. J Med Genet 2011;48(6):422-425

61 Chiang SC, Hwu WL, Lee NC, Hsu LW, Chien YH. Algorithm for Pompe disease newborn screening: results from the Taiwan screening program. Mol Genet Metab 2012;106(3):281-286

62 Labrousse P, Chien YH, Pomponio RJ, et al. Genetic heterozygosity and pseudodeficiency in the Pompe disease newborn screening pilot program. Mol Genet Metab 2010;99(4):379-383

63 Liao HC, Chiang CC, Niu DM, et al. Detecting multiple lysosomal storage diseases by tandem mass spectrometry-a national newborn screening program in Taiwan. Clin Chim Acta 2014;431:80-86

64 Mechtler TP, Stary S, Metz TF, et al. Neonatal screening for lysosomal storage disorders: feasibility and incidence from a nationwide study in Austria. Lancet 2012;379(9813):335-341

65 Spada M, Pagliardini S, Yasuda M, et al. High incidence of lateronset Fabry disease revealed by newborn screening. Am J Hum Genet 2006;79(1):31-40

66 Wittmann J, Karg E, Turi S, et al. Newborn screening for lysosomal storage disorders in Hungary. JIMD Rep 2012;6:117-125

67 Inoue T, Hattori K, Ihara K, Ishii A, Nakamura K, Hirose S. Newborn screening for Fabry disease in Japan: prevalence and genotypes of Fabry disease in a pilot study. J Hum Genet 2013;58(8):548-552

68 Duffner PK, Caggana M, Orsini JJ, et al. Newborn screening for Krabbe disease: the New York State model. Pediatr Neurol 2009; 40(4):245-252, discussion 253-255

69 Hopkins PV, Campbell C, Klug T, Rogers S, Raburn-Miller J, Kiesling J. Lysosomal storage disorder screening implementation: findings from the first six months of full population pilot testing in Missouri. J Pediatr 2015;166(1):172-177

70 Scott CR, Elliott S, Buroker N, et al. Identification of infants at risk for developing Fabry, Pompe, or mucopolysaccharidosis-I from newborn blood spots by tandem mass spectrometry. J Pediatr 2013;163(2):498-503

71 Burton B, Charrow J, Angle B, Widera S, Waggoner D. A pilot newborn screening study for lysosomal storage disorders (LSD) in Illinois. Mol Genet Metab 2012;105:S23-S24

72 Moyer VA, Calonge N, Teutsch SM, Botkin JR; United States Preventive Services Task Force Expanding newborn screening: process, policy, and priorities. Hastings Cent Rep 2008;38(3):32-39

73 Therrell BL, Johnson A, Williams D. Status of newborn screening programs in the United States. Pediatrics 2006;117(5 Pt 2): S212-S252

74 Dees R, Kwon J. The Ethics of Krabbe Screening. Public Health Ethics 2013;6:114-119

75 Ross LF, Waggoner DJ. Parents: critical stakeholders in expanding newborn screening. J Pediatr 2012;161(3):385-389

76 Timmermans S, Buchbinder M. Patients-in-waiting: living between sickness and health in the genomics era. J Health Soc Behav 2010;51(4):408-423

77 Borry P, Stultiens L, Nys H, Cassiman JJ, Dierickx K. Presymptomatic and predictive genetic testing in minors: a systematic review of guidelines and position papers. Clin Genet 2006;70(5):374-381

78 Levy HL. Newborn screening: the genomic challenge. Mol Genet Genomic Med 2014;2(2):81-84 
